\title{
THE EFFECT OF THERMAL MANIPULATION OF (ROSS 308) BROILER BREEDER EGGS DURING EARLY \& LATE EMBRYOGENESIS STAGES ON PRODUCTIVE PERFORMANCE OF HATCHIE CHICKS AT HEAT STRESS CONDITION.
}

ALI, D., IBRAHIM, I. and AL SARDARY, S

Animal Production Department, Mosul University, Agriculture and Forestry

College- Mosul, IRAQ

Email:1diyar1972@yahoo.com

\begin{abstract}
The study was conducted in Hatchery -private sector- in Qushtapa, Erbil, from 24-5-2016 to 14-6-2016. The hatched chicks were reared from(14/6/2016 to 26/7/2016) in one of the halls of Department of Animal Production in College of Agriculture/ Salahadding University-Erbil within total 63 days.

This study was conducted to investigate the effect of thermal manipulation (TM) during different embryogenesis stages of broiler breeder eggs as at embryonic days (ED): T2 (1-5), T3 (19-21) and T1 was control (no TM) on hatching results and subsequent chick characteristics and broiler productive performance of thermally conditioned chicks (exposed to $38.0 \pm 2{ }^{\circ} \mathrm{C}$ for 12 hours/day) at $21^{\text {st }}$ day of age. One thousand eight hundred (1800) Ross-308 eggs from twenty seventh weeks old imported were used. Eggs were randomly divided into three treatments with four replicates per each treatment (600 eggs/ treatment). Two identical incubators were used. In the first incubator all eggs were incubated at $37.7{ }^{\circ} \mathrm{C}$ and $60-65 \%$ relative humidity $(\mathrm{RH})$. The eggs thermally treated were transferred into the second incubator and was kept at $38.2{ }^{\circ} \mathrm{C}$ and $60-65 \%$ RH. After four (4) hours (hrs.) of thermal treating, the eggs were returned to the first incubator, immediately. It was found that thermal manipulation did not affect the hatchability percentage of total and fertile set eggs, normal bird's percentage, and chicks' quality. Post-hatching, 270 day-old chicks were randomly assigned according to treatment groups within hatching process. Chicks were distributed into three treatments with three replicates-groups-, with thirty chicks per each replicate. All treatment groups were subjected to thermal conditioning of $38 \pm 2{ }^{\circ} \mathrm{C}$ for $12 \mathrm{hrs}$. /day for a week, from day $21^{\text {st }}$ post-hatching. After exposure body temperature of birds were measured. Live body weight, bodyweight gain, feed consumption, feed conversion ratio and mortality were recorded on weekly basis. Production index, dressing percentage and carcass cuts percentages were measured at 35 and 42 days of age of broiler chicks. The overall data showed the following results:

1- $\quad \mathrm{T} 2$ showed significantly $(\mathrm{p} \leq 0.05)$ higher relative growth than control group and $\mathrm{T} 3$.

2- T3 and control group showed significantly higher feed conversion ratio than T2, so $\mathrm{T} 2$ had a better cumulative ratio.

3- T2 and T3 showed significantly $(\mathrm{p} \leq 0.05)$ lower rectal temperature than control group.

4- T2 had the higher production index than T3 and control group at marketing age of 35 days.
\end{abstract}


5- Control group showed significantly lowest cumulative mortality percentage than $\mathrm{T} 2$.

In the embryogenesisdevelopment, the incubation temperature is increased by $0.5^{\circ} \mathrm{C}$ for $4 \mathrm{hrs}$. This thermal treatment of the body temperature leads to decrease of the chicks' temperature at day 42, as compared with the control group. As a result it confirms the acquisition of thermo tolerance in thermally manipulated groups.

Key-Words: Epigenetic adaption, Thermal manipulation, Early age heat conditioning, Performance, Thermo-tolerance.

Received: 8/11/2018, Accepted: 16/5/2019

\section{INTRODUCTION}

Poultry meat consumption is expected to be raised by $60 \%$ over the next 20 years and will be the most important meat category worldwide by $2030 \mathrm{FAO}$ (2010) Genetic selection strategies which has significantly Improved growth of meattype broiler chickens during recent decades, but lack of a parallel development of the visceral systems causes significant difficulties for broiler chickens in coping with high temperature challenges, due to the large body mass and high rate of metabolism associated with rapid growth Cangar,A.Z.et al., (2008).Thermotolerance can be defined as the ability of organisms to survive and overcome lethal thermal stress from a previous heat exposure Moseley,P.L.(1997). For Increasing the thermo-tolerance capacity of the birds and also inhibition of economic losses as a result of heat stress, the adaptation to ambient conditions depends on a mechanism called epigenetic adaptation when chicken can be better conditioned to thermal stress tolerance during the pre-hatching and early posthatching period through epigenetic mechanism by exploiting the immaturity of temperature regulation in embryos and early post-hatch birds by thermal conditioning at critical developmental phases Yahav,S.andJ. P.Mcmurtry(2001)and these methods have provided some suitable results for broiler industry Nickelmann, M. and B. Tzschentke(2002). Under these conditions there is a period when the thermo-tolerance can be enhanced by thermal conditioning, without impairing the performance Yahav,S.andS.Hurwitz(1996).

\section{MATERIALS AND METHODS}

The chicks of this experiment were exposed to thermal manipulation by increasing $0.5^{\circ} \mathrm{C}$ from standard temperature for four hours daily during embryogenesis in early and late embryonic stages, the heat exposing on treatments were as follow:

Heat exposing treatment started from ED (1-5) incubation periods and ED (19-21) of hatching period, respectively. While, T3: Control: no $\mathbf{T M}=$ exposed to standard conditions $\left(37.7{ }^{\circ} \mathrm{C}\right.$ and $\left.65-70 \% \mathrm{RH}\right)$ in incubator and $\left(37.3,37.1\right.$ and $37.0{ }^{\circ} \mathrm{C}$ during days 19th, 20th and 21st of hatching, respectively with $75-80 \% \mathrm{RH}$ ) in hatchery.Two hundred seventy (270) a day-old hatched chicks (Ross-308) reared in poultry research hall of Grdarasha farm/ Animal Resources Department/ College of Agriculture/ Salahaddin University from 14/6/2016 to 26/7/2016. The house was divided into 9 floor cages $(2 * 1.7) \mathrm{m}^{2}$. The chicks of both treatments and control groups were randomly divided into 3 replicates / group, three cages for each 
treatment. The chicks were reared at standard environment temperature till 21 day old, all chicks were exposed to heat conditioning of $\left(38 \pm 2^{\circ} \mathrm{C}\right)$ from 21 days old for 12 hours/day for one week till 28 days old, after that the birds exposed to elevated temperature $26 \pm 2^{\circ} \mathrm{C}$ till marketing age. A constant photoperiod of 23L: 1D hours during period was provided. Feed and water were provided ad libitum along the experiment period. Birds were fed three rations; starter from (1-22) days, grower from (23-36) days and finisher from (36-42) days. The analyzed metabolic energy (ME kcal) and crude protein (CP \%) for starter, grower and finisher was (2925 kcal, $22-23 \%),(3040 \mathrm{kcal}, 20-21 \%)$ and (3100 kcal, 18-19\%) respectively. Vaccination program used during the experiment was according to Intervet Schering- Plough Animal Health. The experiments were executed as a complete randomized design (CRD), all data analyzed using the SAS,Statisticalanalysissystem(2001). Duncan`s multiple range tests were used to compare differences among treatment means Duncan, D. B. (1955).

\section{RESULTS AND DISCUSSION}

Table (1) shows that $\mathrm{T} 1$ had significantly $(\mathrm{P} \leq 0.05)$ higher relative growth compared to $\mathrm{T} 2$ and control group. While $\mathrm{T} 2$ showed significantly $(\mathrm{P} \leq 0.05)$ lower relative growth than other thermally manipulated groups and the control group. According to Willemsen,H.;et al.,(2008) development during the first week of life of a chick was important to their future performance. Physiological processes such as cell hyperplasia and hypertrophy, maturation of the thermoregulatory and immunological systems, growth and differentiation of the gastrointestinal tract will subsequently markedly influence BW until market age.

Table (2) shows that there were no significant differences in live body weight (BW) at day $35^{\text {th }}$ and $42^{\text {nd }}$ of age. The non-significant differences in BW at 6th week were due to the changes of kinetics of satellite cell prolification which improved numerically BW at slaughter age. Further, in embryos as well as chicks of meattype poultry mild heat exposure if applied during developmental 'Critical periods' environmental influences can change the programming of respective body Functions Tzschentke,B.and A.Plagemann(2006).

Accumulative BWG (1-35d) was noted that $\mathrm{T} 1$ was significantly $(\mathrm{P} \leq 0.05)$ lower than control group. The difference in weight gain among treated groups may be due to different environmental Conditions in the hatcher, chicks hatching at different moments within the hatch window are subjected to Different conditions for a variable length of time, which may lead to different chick physiology at hatch and at the typical moment of chick collection and also to different growth post-hatch Van deVen, L. (2012). Also the reduction in weight gain during and immediately after conditions to high temperatures may be due to that the chicken directs the energy used for its growth to maintain body temperature within normal range with minimal response to heat stress and ensuring the organic function of tissues within physiological Limits Lin,H.;et al.,(2006). As well as, high rearing temperature decrease in weight gain may due to that heat stress Increase serum corticosterone level (which stimulate much higher muscle breakdown, that contributed to the lower BWG observed in birds kept in heat stress than those in a thermoneutral 
environment Quinteiro-Filho,W.M.;et al.,(2010). In poultry it is believed that less weight gain in the heat stressed groups due to reduction in intestinal absorption efficiency was partly explained by decreased metabolic utilization of nutrients,Increased heat production, reduced protein retention, and enhanced lipid deposition Baziz,A.H.;et al.,(1996). Accumulative FI (1-35d) and (1-42d), T1 consumed significantly $(\mathrm{P} \leq 0.05)$ less feed than other treatment groups (Table 2). The most influential factors affecting feed consumption of chicks have been suggested to be related to the incubation and brooding temperature Leksrisompong, N.; et al.,(2009). The possible causes of feed intake reduction for heat treated groups may be due to the effect of metabolic heat production which is one of the factors that cause feed intake reduction in birds maintained in hot temperatures Siqueira,J. C.;R. F. M. Oliveira;J. L. Donzele etal.(2007). Moreover, may probably due to that chickens maintained at the higher temperatures, generally responded by increasing their respiratory rate, therefore, the period of time for their consumption of feed decreased Han,A.Y.; et al.,(2010).. As well as, in poultry the heat stressed groups have low appetite and lower feed intake, as it may be a defense mechanism to help reduce heat production Sohail,M.U.;et al.,(2012)..

Feed conversion is an index associated with both feed consumption and weight gain. In accumulative FCR (1-42d) T1 had significantly $(\mathrm{P} \leq 0.05)$ better FCR than $\mathrm{T} 2$ and control. Also the results indicated that there were no significant differences among all the thermally manipulated groups as compared to each other and to control group in FCR in accumulative FCR (1-35) (Table 2). In accumulative mortality percentage (1-35 and 1-42) control group had significantly $(\mathrm{P} \leq 0.05)$ lower mortality percentage than $\mathrm{T} 1$ (Table 2). The result of cumulative mortality percentage of $\mathrm{T} 2$ agreed with Hulet, R.; et al.,(2007). Also may early age heat conditioning relieved the negative effects of heat stress on viability and ability of broilers to tolerate the high temperatures Toplu,H.D.O.;et al.,(2014). Whereas the increased mortality percentage during rearing period in T1 and T2 may be related to the negative effects of elevated temperature during embryogenesis on the cardiovascular system as heart size, heart weight and energy metabolism capabilities in cardiac tissue and this may increase the incidence of broiler problems such as sudden death syndrome and ascites may be related to metabolic disorders that are associated with cardiovascular development later in life Fernandes, J. I. M.; et al., (2013).

Table (2) clarifies that $\mathrm{T} 1$ represented significantly $(\mathrm{P} \leq 0.05)$ higher $\mathrm{PI}$ than $\mathrm{T} 2$ and control groups. While, at the duration of 1-42 days, there was non-significant among all treatments. The improvement in production index may be related to overall improvement in average body weight and mortality percentage of broilers during rearing period. Heat stress has a negative effect on poultry production efficiency Cahaner, A.; et al.,(2008). Many researches showed that manipulation of incubation temperature intermittently during broiler embryogenesis with low magnitude may have a long-lasting influence on improving poultry performance [Piestun, Y.;et al.,(2011)., Piestun,Y.;et al., (2013b), Tatge,S.;et al.,(2014)]. In contrast Collins,K.E.;et al., (2013) demonstrated that TM adversely affected broiler performance. 
Table (3) shows carcass traits at day $42^{\text {nd }}$, dressing percentage without giblets were significantly $(\mathrm{P} \leq 0.05)$ higher in $\mathrm{T} 1$ than $\mathrm{T} 2$ and control group. Carcass traits at day $35^{\text {th }}$, Breast percentage were significantly $(\mathrm{P} \leq 0.05)$ higher in $\mathrm{T} 1$ than $\mathrm{T} 2$ and control group. Thigh percentage was significantly $(\mathrm{P} \leq 0.05)$ higher in $\mathrm{T} 1$ than control group. As well as, at day $35^{\text {th }}$ there were no significant differences among all thermally manipulated groups as compared to each other and to control group in percentages of dressing with giblet parts and abdominal fat. Results of $\mathrm{T} 1$ are agreement with Piestun, Y.;et al.,(2013a)that heating the embryos improved the relative breast muscle slightly at days $35^{\text {th }}$ days. At day $42^{\text {nd }}$, dressing percentage without giblets was significantly $(\mathrm{P} \leq 0.05)$ higher in $\mathrm{T} 1$ than other treatments. While there were no significant differences among all thermally manipulated groups as compared to each other and to control group in live body weight and percentages of dressing with giblets, and breast at day $42^{\text {nd }}$. At day $42^{\text {nd }}$ the results of [25] confirmed the result of $\mathrm{T} 2$ that increasing incubation temperature $1{ }^{\circ} \mathrm{C}$ above the standard during the last three days of incubation numerically increased body weight at slaughter than control. The results of treated (T1) groups for dressing without giblets percentage were confirmed by the results of El-Moniary,M.M. A.;et al., (2010) increased carcass percentage slightly at days $42^{\text {nd }}$. The thigh percentage results of T2 were in agreement with the results of El-Moniary,M.M. A.;et al., (2010)at day $42^{\text {nd }}$. In contrast, the results of $\mathrm{T} 2$ at day $42^{\text {nd }}$. Results of $\mathrm{T} 1$ was matched the results of Han,A.Y.; et al.,(2010) where found that TM of $38.5^{\circ} \mathrm{C}$ from ED4 through ED7 resulted smaller fat pads and adipocytes than controls. Elevating incubation temperature during embryogenesis improved productive characteristics of adult chickens because have a stimulatory effect on the proliferation of satellite cells (muscle cells) that is considered the precursor of myogenic cells in the embryo or post-hatching muscles, which effects on increased growth and development of skeletal musculature in the postnatal period of development Piestun,Y.;et al.,(2013b) by changing the rate of myoblast proliferation resulting in increased number of cells within a diameter and/or numbers in the pectoral major muscle in the heat treated embryos Piestun, Y.;et al.,(2011).

Table (4)shows that there is no significant difference among all thermally manipulated groups as compared to each other and to control group in body temperature at hatch, day 35 th of age. At day 42 nd control group had significantly $(\mathrm{P} \leq 0.05)$ higher body temperature than $\mathrm{T} 1$ and $\mathrm{T} 2$.

The reduced rectal temperature in $\mathrm{T} 1$ group compare to control at day $42^{\text {nd }}$, may be due to increased rearing temperature causes a decrease in the concentration of T2 hormones in blood plasma and a decrease in metabolic rate of broiler chickens generally led to lower body temperature at normal or high temperature Muchacka,R.;et al.,(2012). Nevertheless, may be thermal conditioning in broiler chickens enhanced heat tolerance Wang,S.andF. W.Edens(1998).

\section{CONCLUSIONS AND RECOMMENDATIONS}

Relying on the present results of exposing the broiler breeder eggs to intermittent thermal manipulation (TM) by $0.5^{\circ} \mathrm{C}$ above the optimum incubation temperature 
during early and late embryogenesis periods, followed by post-hatch thermal conditioning (TC) of chicks, it was concluded that:

1- Relative growth percentage at 1 st week age as an indicator for future performance.

2- All thermally manipulated birds showed a significant reduction in 42 days body temperature compared to control, which is an indicator for best acquisition of thermotolerance.

3- Production index as an indicator for bird's subsequent performance, ED (1-5) were superior to and control groups during the first and the second marketing age, respectively.

4- In mixed (males and females) rearing thermal Manipulation had no significant effect on dressing percentage with giblets generally at 35 and 42 days, also dressing percentage without giblets at 35 days, while at 42 days thermally manipulated groups at ED (1-5) was significantly higher than other treatments.

So we recommend that:-

1- Determination of relative growth at 1st week is recommended in predicting the subsequent productive performance of broilers.

2- Thermal manipulation is recommended generally as a method for better subsequent thermo-tolerance.

4- To obtain higher percentages of main carcass parts at 35 days it is recommended to apply thermal manipulation during both ED 1-5 while using thermal manipulation during ED (19-21) and control are advised in getting higher Percentages of main carcass parts at 42 days.

5- More future investigations are needed to have better idea about thermal manipulation and thermal Conditioning in breeders, layers and broilers.

Table (1): The Effect of Thermal Manipulation On relative growth (\%) of broiler chicks during first week of age.

\begin{tabular}{|c|c|c|c|c|}
\hline \multirow{2}{*}{ RG } & \multicolumn{2}{|c|}{} & \multirow{2}{*}{ L.S. } \\
\cline { 2 - 4 } & T1 & T2 & Control & \multirow{2}{*}{$*$} \\
week & 413.1 & 356.0 & 394.6 & \\
\hline
\end{tabular}

a, b, c : means within each row had the different subscript were differ significantly $(\mathrm{P} \leq 0.05)$. 
Table (2): The Effect of Thermal Manipulation On accumulative body weight (g), body weight gain (g/bird), feed consumption, feed conversion ratio, mortality percentage and production index during two rearing period (1-35d) and (1-42d) of broiler chicks.

\begin{tabular}{|c|c|c|c|c|}
\hline \multirow{2}{*}{ Accumulative } & \multicolumn{3}{|c|}{ Treatment } & \multirow{2}{*}{ L.S. } \\
\cline { 2 - 4 } & T1 & T2 & Control & \\
\hline BW (1-35d) & $2141.5 \pm 65.6^{\mathrm{a}}$ & $2146.2 \pm 59.6^{\mathrm{a}}$ & $2110.6 \pm 56.1^{\mathrm{a}}$ & N.S \\
\hline BW (1-42d) & $2771.8 \pm 89.7^{\mathrm{a}}$ & $2842.1 \pm 86.7^{\mathrm{a}}$ & $2834.0 \pm 97.3^{\mathrm{a}}$ & N.S \\
\hline BWG (1-35d) & $2044.6 \pm 7.8^{\mathrm{b}}$ & $2081.6 \pm 24.8^{\mathrm{ab}}$ & $2104.5 \pm 7.8^{\mathrm{a}}$ & $*$ \\
\hline BWG (1-42d) & $2735 \pm 12^{\mathrm{a}}$ & $2793.0 \pm 28.7^{\mathrm{a}}$ & $2808.2 \pm 25.2^{\mathrm{a}}$ & N.S \\
\hline FI (1-35d) & $2867.0 \pm 56.3^{\mathrm{b}}$ & $3020.7 \pm 31.3^{\mathrm{a}}$ & $3033.9 \pm 10.8^{\mathrm{a}}$ & $*$ \\
\hline FI (1-42 d) & $3958.8 \pm 65.6^{\mathrm{b}}$ & $4185.9 \pm 26.9^{\mathrm{a}}$ & $4207.9 \pm 26.9^{\mathrm{a}}$ & $*$ \\
\hline FCR (1-35d) & $1.402 \pm 0.02^{\mathrm{a}}$ & $1.451 \pm 0.01^{\mathrm{a}}$ & $1.498 \pm 0.01^{\mathrm{a}}$ & N.S \\
\hline FCR (1-42d) & $1.447 \pm 0.03^{\mathrm{b}}$ & $1.500 \pm 0.02^{\mathrm{a}}$ & $1.499 \pm 0.04^{\mathrm{a}}$ & $*$ \\
\hline Mortality(1-35d) & $10.0 \pm 3.69^{\mathrm{a}}$ & $8.14 \pm 2.84^{\mathrm{ab}}$ & $2.96 \pm 0.83^{\mathrm{b}}$ & $*$ \\
\hline \& (1-42d) & & $373.03 \pm 13.5^{\mathrm{b}}$ & $379.82 \pm 3.5^{\mathrm{b}}$ & $*$ \\
\hline PI 35d & $383.17 \pm 15.8^{\mathrm{a}}$ & $413.33 \pm 10.5^{\mathrm{a}}$ & $408.34 \pm 4.6^{\mathrm{a}}$ & N.S \\
\hline PI 42 d & $419.22 \pm 11.7^{\mathrm{a}}$ & $4.05)$. \\
\hline
\end{tabular}

a, b, c : means within each row had the different subscript were differ significantly $(\mathrm{P} \leq 0.05)$.

Table (3): The Effect of Thermal Manipulation on carcass traits of mixed broilers at 35 and 42 days.

\begin{tabular}{|c|c|c|c|c|c|}
\hline \multirow{2}{*}{ Carcass traits } & \multirow{2}{*}{ Age } & \multicolumn{3}{|c|}{ reatment* } & \multirow{2}{*}{ LS } \\
\cline { 3 - 5 } & & T1 & T2 & Control & \\
\hline Live body & 35 & $2141.5 \pm 65.6^{\mathrm{a}}$ & $2146.2 \pm 59.6^{\mathrm{a}}$ & $2110.6 \pm 56.1^{\mathrm{a}}$ & $*$ \\
weight (gm) & 42 & $2771.8 \pm 89.7^{\mathrm{a}}$ & $2842.1 \pm 86.7^{\mathrm{a}}$ & $2834.0 \pm 97.3^{\mathrm{a}}$ & N.S \\
\hline Dressing\% & 35 & $77.7 \pm 0.3^{\mathrm{a}}$ & $78.9 \pm 0.8^{\mathrm{a}}$ & $79.2 \pm 2.4^{\mathrm{a}}$ & N.S \\
with giblets & 42 & $81.1 \pm 0.4^{\mathrm{a}}$ & $80.9 \pm 1.2^{\mathrm{a}}$ & $79.6 \pm 0.4^{\mathrm{a}}$ & N.S \\
\hline Dressing\% & 35 & $72.6 \pm 0.3^{\mathrm{a}}$ & $73.4 \pm 0.9^{\mathrm{a}}$ & $73.9 \pm 2.3^{\mathrm{a}}$ & N.S \\
without giblets & 42 & $75.7 \pm 0.4^{\mathrm{a}}$ & $74.5 \pm 0.4^{\mathrm{b}}$ & $74.2 \pm 0.4^{\mathrm{b}}$ & $*$ \\
\hline Giblets \% (liver, heart and & 35 & $7.6 \pm 0.2^{\mathrm{a}}$ & $8.5 \pm 0.9^{\mathrm{a}}$ & $8.5 \pm 0.4^{\mathrm{a}}$ & N.S \\
\hline gizzard) & 42 & $7.7 \pm 0.4^{\mathrm{a}}$ & $8.69 .1 \pm 1.4^{\mathrm{a}}$ & $7.9 \pm 0.4^{\mathrm{a}}$ & N.S \\
\hline Breast \% & 35 & $36.8 \pm 0.3^{\mathrm{a}}$ & $34.9 \pm 0.4^{\mathrm{b}}$ & $34.9 \pm 0.6^{\mathrm{b}}$ & $*$ \\
& 42 & $35.3 \pm 0.5^{\mathrm{a}}$ & $36.4 \pm 0.5^{\mathrm{a}}$ & $36.6 \pm 0.5^{\mathrm{a}}$ & N.S \\
\hline Thighs \% & 35 & $28.8 \pm 0.3^{\mathrm{a}}$ & $27.9 \pm 0.3^{\mathrm{ab}}$ & $27.6 \pm 0.4^{\mathrm{b}}$ & $*$ \\
& 42 & $28.6 \pm 0.4^{\mathrm{a}}$ & $29.5 \pm 0.3^{\mathrm{a}}$ & $29.2 \pm 0.4^{\mathrm{a}}$ & N.S \\
\hline
\end{tabular}

a, b, c : means within each row had the different subscript were differ significantly $(\mathrm{P} \leq 0.05)$.

* Main parts= (breast $\&$ thighs), Secondary parts $=($ back, wing $\&$ neck $)$. 
Table (4): The Effect of Thermal Manipulation on Productive Performance of Hatchie Chicks at Heat Stress Condition. On body temperature $\left({ }^{\circ} \mathrm{C}\right)$.

\begin{tabular}{|l|c|c|c|c|}
\hline \multirow{2}{*}{ Age $(\mathrm{d})$} & \multicolumn{3}{|c|}{ Treatmen } & \multirow{2}{*}{ L.S. } \\
\cline { 2 - 4 } & T1 & T2 & Control & \\
\hline 35 & $40.8 \pm 0.18^{\mathrm{a}}$ & $40.7 \pm 0.13^{\mathrm{a}}$ & $40.9 \pm 0.13^{\mathrm{a}}$ & N.S \\
\hline 42 & $40.7 \pm 0.12^{\mathrm{b}}$ & $40.6 \pm 0.15^{\mathrm{b}}$ & $41.5 \pm 0.16^{\mathrm{a}}$ & $*$ \\
\hline
\end{tabular}

$\mathrm{a}, \mathrm{b}, \mathrm{c}$ : means within each row had the different subscript were differ significantly $(\mathrm{P} \leq 0.05)$.

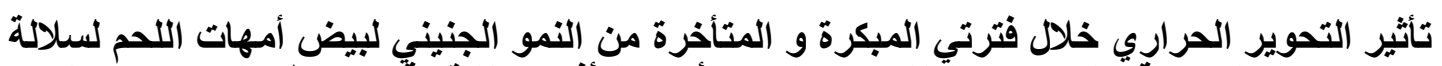
ROSS 308

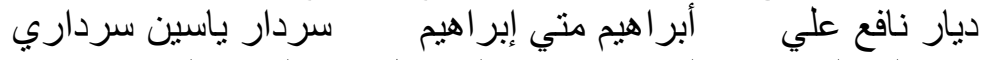

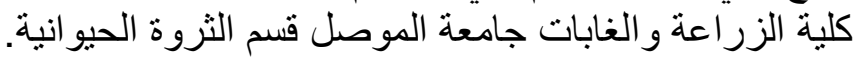
Email:1diyar1972@yahoo.com

\section{الخلاصة}

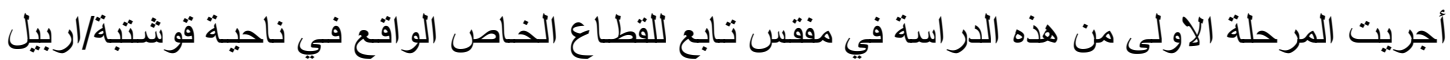

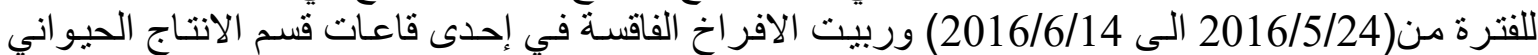

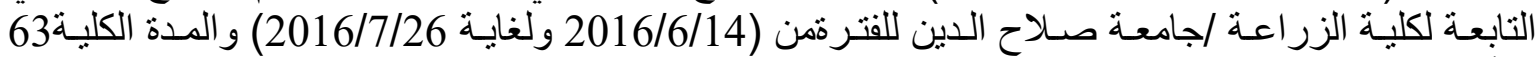

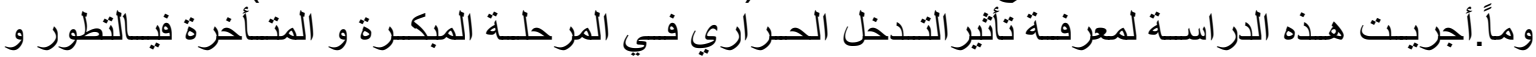

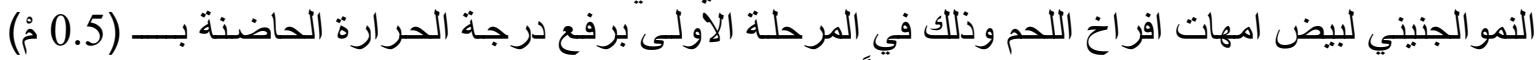

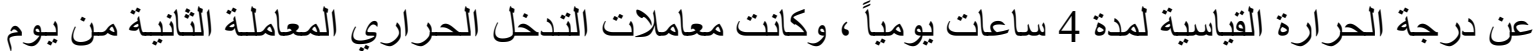

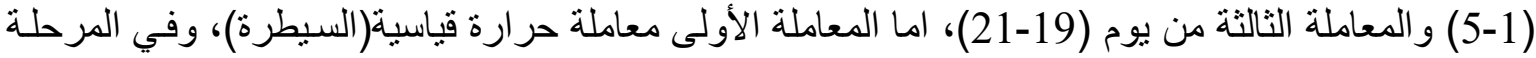

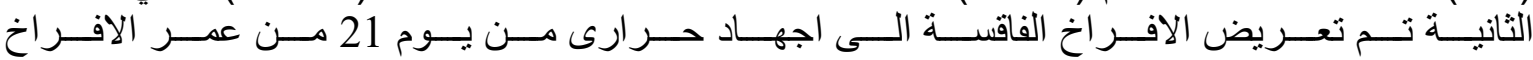

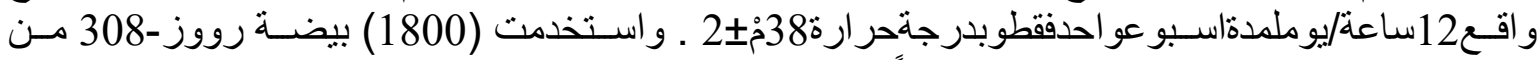

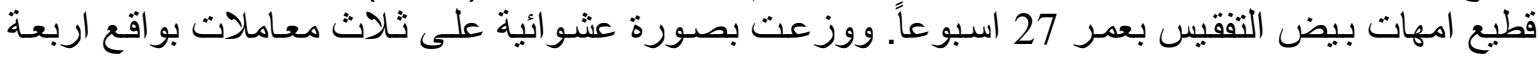

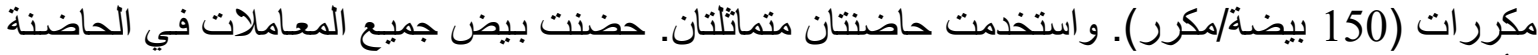

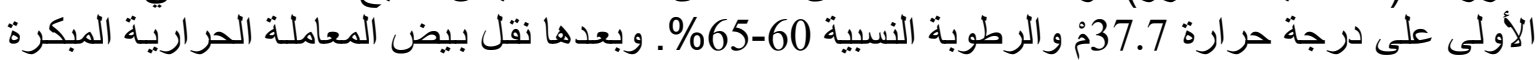

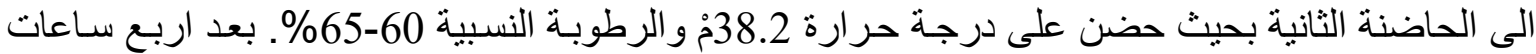

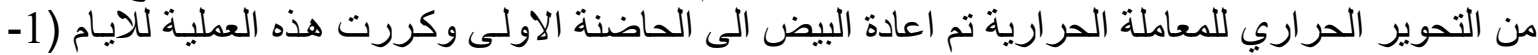

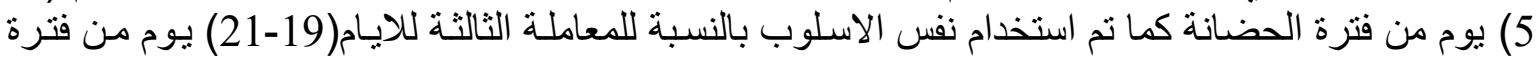

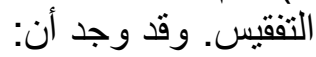

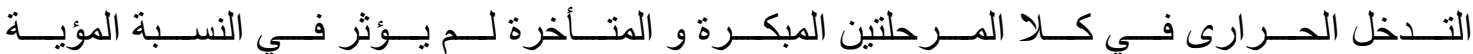

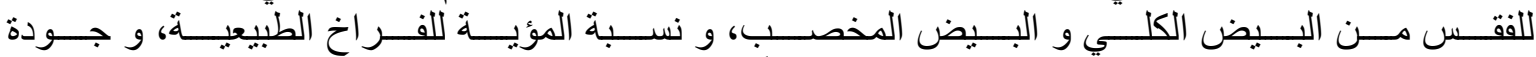

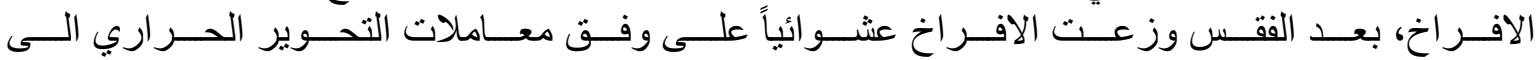

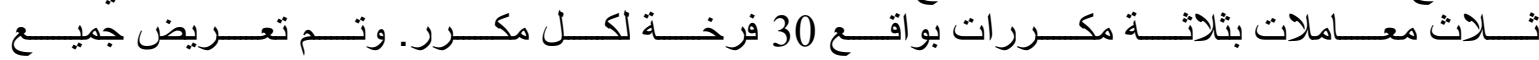

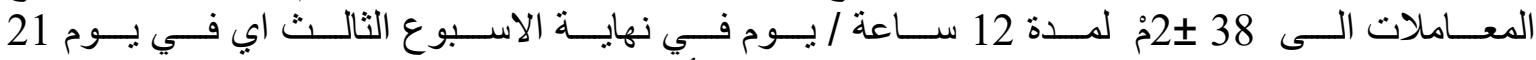

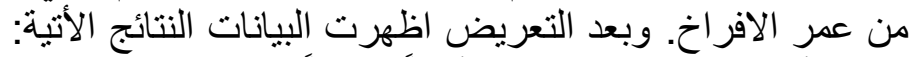

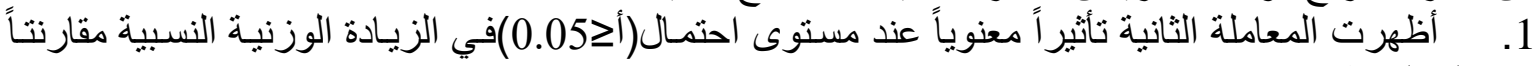
بمعاملة السبطرة.

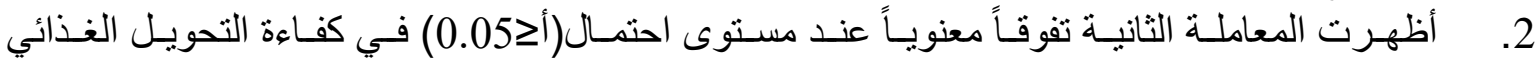

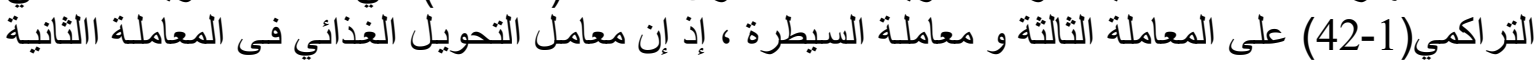




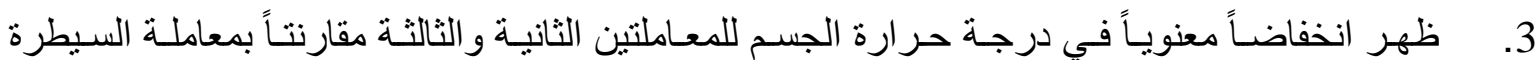

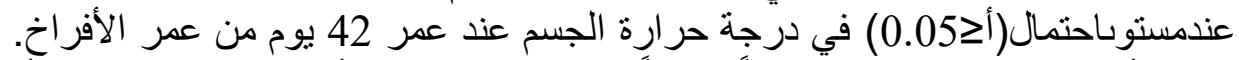

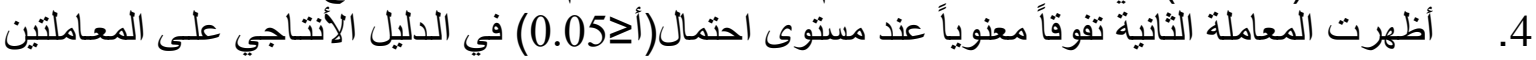

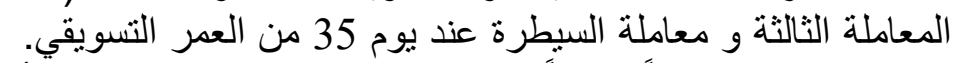

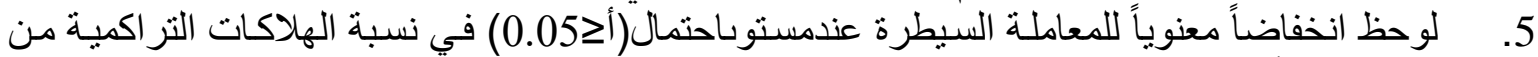
يوم (42-1) قياساً بالمعاملتين الثانية و الثنالثة.

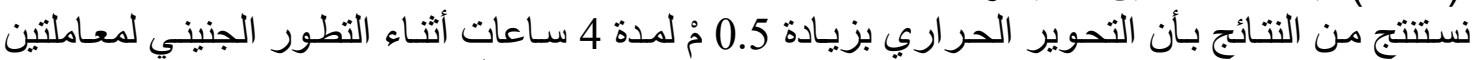

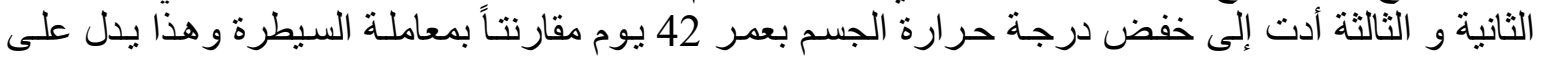
اكتساب قدرة مقاومة الحرارة. تاريخ الاستلام :2018/11/8، ناريخ القبول البحث: 2019/5/16

\section{REFERENCES}

Baziz, A. H.; P. A. Geraert; J. C. F. Padilha and S. Guillaumin (1996). Chronic heat exposure enhances fat deposition and modifies muscle and fat repartition in broiler carcasses. Poultry Science.75:505-513

Cahaner, A. ; J. A. Ajuh; M. Siegmund- Schultze; Y. Azoulay; S. Druyan and A. V. Zarate (2008).Effects of the genetically reduced feather coverage in naked neck and featherless broilers on their performance under hot conditions. Poultry Science. 87:2517-2527.

Cangar, A. Z.; J. M. Aerts; J. Buyse and D.Berckmans (2008). Spatial distribution of surface temperatures and beat loss in broiler chickens. Livestock Environment, Iguassu Falls, Brazil.

Collins, K. E.; B. J. Jordan; B. L. McLendon; K. J. Navara; R. B. Beckstead and J. L. Wilson (2013).No evidence of temperature-dependent sex determination or sex-biased embryo mortality in the chicken.Poultry Science.92(12):3096-3102.

Duncan, D. B. (1955).Multiple range and multiple F.Biometrics 11:1-42

El-Moniary, M. M. A.; A. A. Hemid; I. El- Wardany; A. E. Gehad and A. Gouda (2010).The effect of early age heat conditioning and some feeding programs for heat-stressed broiler chicks on productive performance. World J. of Agricultural Sciences. 6 (6): 689-695.

FAO (2010). FAO STAT consumption data, http://faostat.fao.org.

Fernandes, J. I. M. ; L. B. Scapini; E. T. Gottardo; A. M. B. Junior; F. E. S. Marques and L. Gruchouskei (2013).Thermal conditioning during the first week on performance, heart morphology and carcass yield of broilers submitted to heat stress. Acta Scientiarum Animal Sciences. 35 (3): 311 319.

Han, A. Y.; M. H. Zhang; X. L. Zuo; S. S.Zheng; C. F. Zhao; J. H. Feng and C. Cheng.Effect of acute heat stress on calcium concentration, proliferation, cell cycle, and interleukin-2 production in splenic lymphocytes from broiler chickens. Poultry Science. $89: 2063-2070$.

Hulet, R.; G. Gladys; D. Hill; R. Meijerhof and

Leksrisompong, N.; H. Romero-Sanchez; P.W. Plumstead; K. E. Brannan; S. Yahav and J. Brake (2009). Broiler incubation. 2. Interaction of incubation and brooding temperatures on broiler chick feed consumption 
and growth. Poultry Science. 88:1321-1329.

Lin, H.; H. C. Jiao; J. Buyse and E. Decuypere (2006). Strategies for preventing heat stress in poultry. World's Poultry Science J., 62:71-86.

Moseley, P. L. (1997). Heat shock proteins and heat adaptation of the whole organism. Journal of Applied Psychology. 83(5): 1413-1417.

Muchacka, R.; I. Skomorucha; E. Sosnówka- Czajka; G. Formicki; A. Greń and Z. Goc (2012).Effect of elevated air temperature on physiological indicators of broiler chickens of different origin. Journal of Microbiology,

Nickelmann, M. and B. Tzschentke (2002).Ontogeny of thermoregulation during the prenatal period in birds.Annual New York Academy of Science. 813: $78-86$.

Piestun, Y.; O. Halevy; D. Shinder; M. Ruzal; S.Druyan and S.Yahav (2011). Thermal manipulations during broiler embryogenesis improves post hatch performance under hot conditions. J.of Thermal Biology. 36:469-474.

Piestun, Y.; S. Druyan; J. Brake and S. Yahav (2013a). Thermal treatments prior to and during the beginning of incubation affect phenotypic characteristics of broiler chickens posthatching. Poultry Science. 92: 882-889.

Piestun, Y.; S. Druyan; J. Brake and S. Yahav (2013b).Thermal manipulations during broiler incubation alter performance of broilers to 70 days of age.Poultry Science. $92: 1155-1163$.

Quinteiro-Filho, W. M.; A. Ribeiro; V. Ferraz-de-Paula; M. L. Pinheiro; M. Sakai; L. R. M. Sa; A. J. P. Ferreira and J. Palermo-Neto (2010). Heat stress impairs performance parameters, induces intestinal injury, and decreases macrophage activity in broiler chickens. Poultry Science. 89:1905-1914.

SAS, Statistical analysis system (2001).User's guide for personal computer.Release 8.2 SAS Institute Inc. Cary, NC, USA.

Siqueira, J. C.; R. F. M. Oliveira; J. L. Donzele et al. (2007).Dietary digestible lysine levels and environmental temperature for growing broiler chickens. Revista Brasileira de Zootecnia. 36: 2054-2062.

Sohail, M. U.; M. E. Hume; J. A. Byrd; D. J. Nisbet; A. Ijaz; A. Sohail; M. Z. Shabbir and H. Rehman (2012).Effect of supplementation of prebiotic mannan oligosaccharides and probiotic mixture on growth performance of broilers subjected to chronic heat stress. Poultry Science. 91: 2235-2240.

supplementation on growth performance, carcass and meat quality characteristics in heat- stressed broilers. Ankara Universitesi Veteriner Fakultesi Dergisi. 61: 295-302.

T. El-Shiekh (2007).Influence of eggshell embryonic incubation temperature and broiler breeder flock age on posthatch growth performance and carcass characteristics. Poultry Science. 86:408-412.

Tatge, S.; K. Melchior; I. Halle; M. Boerjan and B.Tzschentke (2014). Temperature training before hatching: successful method to optimize hatching results and performance in broiler chickens. World Poultry Science Association: Incubation and Fertility Research Group. Lunteren,The Netherlands. 29 $9^{\text {th }}-30^{\text {th }}$ September, 2014. 
Toplu, H. D. O.; A. Nazligül; S. Karaarslan; M. Kaya and O. Yagin (2014). Effects of heat conditioning and dietary ascorbic acid

Tzschentke, B. and A. Plagemann (2006): Imprinting and critical periods in early development. World's Poultry Science J., 62:626-637.

Van de Ven, L. (2012). Effects of hatching time and hatching system on broiler chick development. PhD dissertation. Wageningen Universiy

Wang, S. and F. W. Edens (1998).Heat conditioning induces heat shock protrins in broiler chickens and turkey poults. Poultry Science. 77: 1636-1645.

Willemsen, H.; N. Everaert; A. Witters; L. De Smit; M. Debonne; F. Verschuere; P. Garain; D. Berckmans and V. Bruggeman (2008). Critical assessment of chick quality measurements as an indicator of posthatch performance.Poultry Science. 87: 2358-2366.

Yahav, S. and S. Hurwitz (1996). Induction of thermotolerance in male broiler chickens by temperature conditioning at an early age. Poultry Science. 75 (3):402-406.

Yahav, S. and J. P. Mcmurtry (2001). Thermotolerance acquisition in broiler chickens by temperature conditioning early in life- the effect of timing and ambient temperature. Poultry Science. 80 (12):1662-1666. 